American Journal of Infectious Diseases 3 (4): 248-254, 2007

ISSN 1553-6203

C 2007 Science Publications

\title{
HIV Prevention Intervention Outcome among Minority Adolescents in Court Mandated Drug Treatment
}

\author{
${ }^{1}$ Jessy Devieux, ${ }^{2}$ Robert C. McMahon, ${ }^{1}$ Rhonda Rosenberg and ${ }^{1}$ Robert M. Malow \\ ${ }^{1}$ Florida International University, Miami, Florida \\ ${ }^{2}$ University of Miami, Miami, Florida
}

\begin{abstract}
Problem statement: Delinquent adolescents with substance abuse disorders frequently engage in behaviors that elevate their risk of contracting HIV. Although effective risk reduction interventions are urgently needed, there is uncertainty about the nature of interventions required to produce change. Approach: This study evaluated whether Modified version of Becoming A Responsible Teen (M-BART) produced greater reductions in drug use and sexual risk behaviors than an Anger Management (AM) condition among a mixed gender, culturally diverse sample of adolescents in court-ordered substance dependence treatment. Results: No significant differences were found between M-BART $(n=70)$ and AM $(n=59)$ groups in degree of change between intake and outcome in HIV sex risk or drug use behaviors. However, across groups, meaningful reductions were found in total number of sex partners and in proportions of total unprotected sex acts, unprotected vaginal sex, unprotected oral giving sex acts and unprotected oral receiving sex acts from baseline to follow-up (all p's<0.05). Conclusion: Factors that accounted for meaningful changes across groups and no change between intervention outcomes were discussed. While the M-BART intervention impacted the adolescents directly by teaching skills about how to reduce risky sex, the AM intervention and also impacted higher order factor, impulsivity, linked to risky sex and drug use. Implications for HIV prevention among minority adolescents were discussed.
\end{abstract}

Key words: HIV, AIDS, alcohol, drug use, risky sexual behavior, adolescent offenders,

\section{INTRODUCTION}

Adolescents comprise an increasingly large proportion of those infected with HIV in the US ${ }^{[1]}$. They often do not protect themselves appropriately and tend to engage in sexual experimentation, some with multiple partners $^{[2]}$. Survey data indicate that $32 \%$ of African American and $13 \%$ of Hispanic males engage in sexual activity before the age of 13 , compared to only $7 \%$ among Caucasian males ${ }^{[3]}$. Minority youth face the added burden of individual and neighborhood socioeconomic vulnerabilities and disproportionate HIV rates compared to other adolescents in the United States ${ }^{[4]}$.

Adolescents who have become involved with the juvenile justice system are even more vulnerable as they generally begin to engage in risky behaviors at an earlier age and with greater frequency than their nondetained counterparts ${ }^{[5-7]}$. Research also shows that these adolescents report more permissive attitudes toward $\mathrm{sex}^{[8]}$ and that unprotected sex, lack of knowledge of HIV transmission and an aversion to condom use are common ${ }^{[9]}$.
Other than conduct disorder, substance use diagnoses are the most prevalent among the juvenile justice population ${ }^{[10]}$. The combination of substance use and delinquency increases the risk of engagement in risky sexual behaviors. Teplin and Colleagues ${ }^{[11]}$ found that delinquents with substance use disorders were at very high risk of contracting HIV and were significantly more likely to have engaged in sexual acts that would increase their risk of HIV. Researchers have also found a significant co-occurrence of penetrative sexual behaviors, delinquent behavior and substance use $^{[12]}$.

Becoming A Responsible Teen (BART) is one of the very few evidence-based interventions designed for minority youth with such risk factors and is listed in the CDC Compendium (http://www.cdc.gov/hiv/topics/research/prs/evidencebased-interventions.htm). St. Lawrence et al. ${ }^{[13]}$ developed BART and originally demonstrated its efficacy in reducing HIV risk behavior among African American male and female adolescents in Mississippi. BART provides HIV information and specific training

Corresponding Author: Robert Malow, Biscayne Bay Campus, C I - Suite 260, Florida International University, Miami, Florida 33181-3600 Tel: 305.919.4222 
and practice regarding condom use, partner negotiation, refusal of unwanted sexual invitations and sharing newly acquired information with peers ${ }^{[13]}$. Effective intervention models like the BART, however, remain largely untested with new populations, particularly those who may be challenged in making full use of them, due to contextual barriers (i.e., controlled institutional environments), multiple psychosocial problems, or inadequate supportive services ${ }^{[14-16]}$. Several promising studies of BART effects, though, have been conducted in such challenging circumstances. Lawrence et al. ${ }^{[17]}$ found that among adolescents in residential treatment for substance dependence, standard and motivationally enhanced versions of BART reduced frequency of unprotected vaginal sex and substantially increased rates of sexual abstinence in comparison with an HIV information only condition.

In another study, St. Lawrence et al. ${ }^{[6]}$ randomly assigned adolescent males entering a state reformatory to either an abbreviated $6 \mathrm{~h}$ version of BART or PACT (Positive Adolescent Choices Training), an anger management training module. BART participants received one informational session about STDs, including HIV, followed by training in five skill components: correct condom application, refusal of unwanted sexual initiations, partner negotiation for condom use prior to sexual activity, information provision to peers and self-reinforcement for adaptive behavior. Anger management (PACT) controls received training in six skill components: giving positive feedback, giving negative feedback, accepting criticism, resisting peer pressure, solving problems and conflict resolution. Although no treatment $\mathrm{x}$ time condition effects were found, significant decreases in risky sexual activities and drug use were identified across treatment conditions.

Although available studies suggest that both abbreviated and enhanced versions of BART may be effective in reducing HIV risk behaviors among vulnerable substance abusing adolescents, uncertainty remains about the nature of interventions needed to produce change. Indeed, St. Lawrence et al. ${ }^{[6]}$ study with detained adolescent males would seem to suggest that similar HIV risk reduction outcomes could be obtained with either BART or an anger management intervention. The purpose of this investigation is to examine whether a modified version of BART (MBART) produced greater reductions in sexual risk behaviors among a mixed gender, culturally diverse sample of adolescents in court-ordered substance dependence treatment, compared to an anger management condition (PACT).

\section{MATERIALS AND METHODS}

Recruitment: Recruitment was conducted from 19982002 at a court-ordered drug treatment facility in a large South Florida metropolitan area of Miami-Dade County, a large metropolitan area in South Florida. Recruitment was generally conducted during the first week of entry into either the detention center or treatment facility. After obtaining parental consent and adolescent assent, base line assessments were conducted in private rooms.

Entry criteria for the study included: (1) Being between the ages of 13-19, (2) Being free from severe cognitive or psychiatric impairment that would compromise the ability to complete the assessment as well as the intervention component, (3) Having a history of drug use and (4) Being fluent in spoken English.

Approximately $80 \%$ of adolescents who were approached agreed to participate in the study. The major reasons for non-entry into the study were: (1) Lack of interest, (2) An intention to leave the program too soon to complete the intervention, (3) A belief that the questions were too personal, or (4) A belief that they already knew enough about HIV. A total of 101 subjects were randomized into the BART experimental group (M-BART); 80 into the anger management (AM) condition. Of those who began the intervention, approximately $97 \%$ completed 4 or more of the 6session intervention (99\% completed 4 sessions of MBART condition; 95\% completed AM condition). Thus, 176 subjects completed the baseline assessment and received 4 or more sessions. One hundred twenty-nine subjects were evaluated at three month follow-up.

Sample characteristics: The modal subject was a low income, ethnic or racial minority adolescent who used alcohol and/or marijuana and who resided in the urban inner city. At baseline, the sample included 138 males and 43 females. The mean age of the sample was 15.50 $(\mathrm{SD}=1.63$; range 13-18) and the average level of education was 8.44 years $(\mathrm{SD}=1.43)$. Of participants, $19.3 \%$ were African American, 39.6\% Hispanic, 10.5\% Non-Hispanic White and $30.6 \%$ from other ethnic backgrounds, including Haitian American and other Caribbean heritage. At 3 months, the sample included 129 adolescents, 102 males and 27 females. Fifty-four percent of participants included in the post analyses were in the M-BART group.

Three quarters $(75.4 \%)$ of the sample reported engaging in sexual intercourse in the three months prior to admission to the study. Condom use was reported 
$58.3 \%$ of the time. The mean number of sexual partners within this three month period was $2.82(\mathrm{SD}=8.65)$ and $2.9 \%$ reported being treated for a sexually transmitted disease. Marijuana was the most frequently used substance prior to entry into the study, with average use at 34.81 days $(\mathrm{SD}=32.94)$ in the previous three months. Alcohol was the second most frequently used $(\mathrm{M}=9.20$ (days), $\mathrm{SD}=15.51)$, followed by cocaine use $(\mathrm{M}=5.65$ (days), $\mathrm{SD}=17.35)$. One adolescent reported injection drug use.

Assessment procedures: Baseline assessments were administered one week after participants' admission and clearance from treatment staff that detoxification was adequately completed. This procedure was followed to minimize the effect of detoxification or withdrawal symptoms on test performance and to maximize the accuracy of responses.

All assessment procedures were conducted by experienced interviewers trained to create a process sensitive to gender and cultural issues. Each interview lasted approximately $90 \mathrm{~min}$ and was administered orally to facilitate accurate reporting, full completion and to compensate for any difficulties in reading comprehension. To avoid interviewer drift and other contaminating factors, interviewers received ongoing supervision from a clinical psychologist for the duration of the study. Interviewers were trained to adopt a nonjudgmental attitude during interactions in order to establish rapport and build trust.

Participants were assessed for HIV sex risk behaviors, alcohol and drug use. They were encouraged to respond accurately by being informed that their responses were confidential and would be used to help improve HIV prevention programs for other adolescents.

Measures: Study measures were collected at baseline and three months post-intervention.

Sex risk measures: Sex risk variables were derived using a modified version of sexual risk assessment measures $^{[18]}$ that were adapted $^{[19]}$ and shown to demonstrate adequate validity and reliability in previous studies ${ }^{[20]}$. These measures included retrospective recall of number of sex partners, unprotected sex acts, the subset of unprotected sex acts proximal to substance use and condom use during the previous three months. Frequency was measured as the total number of days during the previous three-month period that the participant engaged in specific sex acts (range 0-92). A tabular format was adopted to facilitate administration and a calendar-based methodology (i.e., a Time-Line Follow-Back Procedure; Sobell and Sobell ${ }^{[21]}$ ) was used to promote accurate recall.

Assessment of drug and alcohol use severity: Participants were asked to indicate (a) which drugs, including alcohol, were used during the past three months and (b) frequency of drug use during the same period. Frequency was measured as the total number of days during the previous three-month period that the participant consumed alcohol and/or specific drugs (range 0-92). These items were adapted from the risk behavior assessment ${ }^{[22]}$. This reporting period was chosen because recall has been shown to be reliable only up to three months ${ }^{[23]}$.

Intervention procedures: Participants were randomly assigned to either a modified BART (M-BART) or Anger Management (AM). The sessions were time matched. Interventions were conducted in a small group format, with each group composed of approximately 48 participants and were usually led by a male-female team of facilitators. Each intervention was comprised of six one-hour sessions which were delivered over a period of 3-6 weeks.

After reviewing numerous HIV prevention curricula; e.g., be proud! Be responsible! ${ }^{[24]}$; adolescents living safely: AIDS awareness, attitudes and actions ${ }^{[25]}$; and STDs and HIV: A guide for today's young adults ${ }^{[26]}$, a decision was made to adapt Becoming A Responsible Teen (BART): An HIV Risk Reduction Intervention for African American Adolescents ${ }^{[27]}$ for use with our diverse group of minority adolescents. BART was modified during 12 trial runs with successively refined versions of the intervention manual. The adolescents' reactions to each draft protocol were obtained through paper and pencil assessments and focus groups. Based on this information, feedback from the interventionists, qualitative and quantitative assessments of the adolescent participants, discussion with community leaders and experts in the fields and new developments in the HIV/AIDS area, we made revisions to the intervention. These revisions included an emphasis on relapse prevention and long-term maintenance strategies.

The final M-BART sessions encouraged participants to actively assist in developing their own risk-reduction strategies (e.g., abstinence, safer sex negotiation, condom use). In addition, group rehearsal and feedback was utilized to refine and individualize risk reduction and relapse prevention strategies. MBART facilitated interactions with the aim of rehearsing strategies to reduce risk and to practice safer 
alternatives. Interventionists also handed out pamphlets and a list of HIV-related resources (e.g., public health clinics, community-based HIV organizations, national hotlines).

The content of M-BART's six sessions focused on various aspects of HIV education and risk reduction skills building. After an initial introduction to the ground rules of group engagement and confidentiality, Session One included a discussion of information regarding prevention of HIV infection, adolescents' personal vulnerability to HIV, an exploration of safer sex attitudes and an exercise to build trust and reduce the participants' discomfort in discussing sexual behavior. Session Two covered, in game format, the tangible risks of contracting HIV, challenging stereotypes about HIV infection and transmission, a discussion and demonstration of condom use application and introduced practical strategies to overcoming the obstacles in using condoms. In Session Three, assertiveness, communication and negotiation skills were modeled and participants were given opportunity to practice these skills in realistic role-play situations. Session Four continued the role-play scenarios and used modeling and group feedback to help adolescents improve their skills in risky sexual situations. Personal sexual values, barriers to safer sex, triggers to risky sexual behaviors and obtaining support from family and friends were explored and discussed in Session Five. And finally, Session Six covered the issue of how alcohol and other substance use increase HIV risk. Further, emphasis was given to encouraging participants to pass on what they had learned to others.

The Anger Management (AM) condition included a one-hour session on preventing HIV. Content of the AM condition included a clear presentation of information regarding the threat, mechanisms of HIV transmission and means to reduce HIV transmission risk. Correct condom use was also discussed. There were five additional one-hour sessions in which participants received training in giving positive and negative feedback, accepting criticism, resisting peer pressure, developing problem communication, problem solving and negotiation skills designed to reduce aggression $^{[28]}$. Following group leader demonstration of skills, participants practiced skills in dyads. The sessions incorporated terminology and a presentation mode tailored to the target population.

Data analyses: Data for M-BART and AM groups were compared at pre-assessment and three months post-assessment using repeated measures analysis of covariance (RMANCOVA) for HIV sexual risk behavior indices and drug and alcohol use. A Log 10 transformation was conducted on percent unprotected sex acts to control for non normality. The SPSS statistical package was used for the analyses ${ }^{[29]}$.

\section{RESULTS}

Preliminary analyses, including t-tests and correlations, were conducted to examine relationships between the covariates (gender and age) and the main outcome variables, sex and drug use.

Covariate analyses: Gender and age were significant covariates in these analyses. Males reported more frequent marijuana use at baseline $(\mathrm{t}=2.14, \mathrm{p}=0.037)$ than females. Females had a higher percentage of unprotected vaginal sex acts at baseline $(\mathrm{t}=2.42$, $\mathrm{p}=0.046)$. Males had a greater number of sex acts at follow-up $(\mathrm{t}=-2.70, \mathrm{p}=0.008)$. Older adolescents used more cocaine at baseline $(r=0.19, \mathrm{p}=0.028)$ and had a higher percentage of unprotected oral receiving sex acts at baseline $(\mathrm{r}=0.20, \mathrm{p}=0.020)$. Number of days in a restricted environment at follow-up was included as a covariate in analyses to control for subjects' opportunity to engage in sex. Intake and follow-up alcohol and drug use values were also used as covariates in all sex risk behavior analyses. Table 1 provides means and standard deviations for sex risk and substance use variables at baseline and follow-up.

Table 1: Means and Standard Deviations for M-BART and AM Groups

\begin{tabular}{|c|c|c|c|c|}
\hline & \multicolumn{2}{|l|}{ AM group $\mathrm{N}=59$} & \multicolumn{2}{|c|}{ M-BART group $\mathrm{N}=70$} \\
\hline & Baseline mean (SD) & Follow-up mean (SD) & Baseline mean (SD) & Follow-up mean (SD) \\
\hline Total No. of sex partners & $3.62(12.14)$ & $1.09(1.58)$ & $2.03(4.19)$ & $1.17(1.59)$ \\
\hline Proportion of total unprotected sex acts & $45.42(40.18)$ & $24.33(37.11)$ & $39.89(40.24)$ & $24.37(36.24)$ \\
\hline Proportion of unprotected vaginal sex acts & $29.85(39.87)$ & $16.71(34.06)$ & $25.91(40.54)$ & $20.87(37.73)$ \\
\hline Proportion of unprotected oral giving sex acts & $35.09(48.15)$ & $19.30(39.81)$ & $20.00(40.34)$ & $12.50(32.71)$ \\
\hline Proportion of unprotected oral receiving sex acts & $48.12(49.97)$ & $21.35(40.31)$ & $48.33(49.76)$ & $22.35(41.33)$ \\
\hline Alcohol use & $8.17(13.91)$ & $4.82(13.67)$ & $10.15(16.79)$ & $2.02(5.12)$ \\
\hline Marijuana use & $33.40(32.57)$ & $7.97(17.36)$ & $39.49(34.66)$ & $5.38(15.33)$ \\
\hline Cocaine use & $5.54(20.94)$ & $1.52(7.32)$ & $5.67(14.70)$ & $0.17(1.34)$ \\
\hline
\end{tabular}


HIV Sex Risk Behaviors: RMANCOVA analyses revealed no differences in degree of change between intake and outcome between M-BART and AM groups in number of sexual partners, proportion of total unprotected sex acts, proportion of unprotected vaginal sex acts, proportion of unprotected oral giving sex acts, or proportion of unprotected oral receiving sex acts (all p's>0.05). Examination of time effects (across M-BART and AM groups) revealed a reduction in total number of partners $(\mathrm{F}(1,119)=11.20$, $\mathrm{p}=0.001)$, a reduction in proportion of total unprotected sex acts $(\mathrm{F}(1,113)=23.74, \mathrm{p}<0.001)$, a reduction in proportion of unprotected vaginal sex $(\mathrm{F}(1,114)=4.64, \mathrm{p}=0.033)$, a reduction in proportion of unprotected oral giving sex acts $(\mathrm{F}(1,116)=10.63$, $\mathrm{p}=0.001)$ and $\mathrm{a}$ reduction in proportion of unprotected oral receiving sex acts $(\mathrm{F}(1,116)=25.34$, $\mathrm{p}<0.001)$ from baseline to follow-up.

Drug use behaviors: RMANCOVA analyses revealed no significant differences in degree of change between intake and follow-up between M-BART and AM groups in alcohol, marijuana or cocaine use (all p's>0.05). Examination of time effects (across MBART and AM groups) revealed a reduction in alcohol use $(\mathrm{F}(1,115)=11.65, \mathrm{p}=0.001)$, a reduction in marijuana use $(\mathrm{F}(1,114)=84.03, \mathrm{p}<0.001)$ and a reduction in cocaine use $(\mathrm{F}(1,113)=8.16, \mathrm{p}=0.005)$ from baseline to follow-up.

\section{DISCUSSION}

There were no significant differences between the M-BART and AM groups in sexual risk and drug use behavior between intake and follow-up, although there were significant reductions in both across groups. There are several factors that may account for the favorable changes in both groups but lack of significant differences between treatment conditions.

First, the AM intervention, which is based on an anger management protocol, targeted skills related to improving impulse control and emotional selfmanagement. Impulsivity has been implicated in the risk behavior of juvenile justice youth, including risky sex and drug use ${ }^{[30]}$. For example, studies with adolescents having conduct and substance use problems showed higher levels of impulsivity compared to community controls ${ }^{[31]}$. While the M-BART intervention likely impacted the adolescents directly by teaching skills about how to reduce risky sex, the AM intervention, may have impacted a higher order factor, impulsivity, linked to risky sex and drug use.
Another possibility is that M-BART participants, trained to share the risk reduction lessons learned with peers, may have contributed to "spill over" effects for participants in the AM condition. St. Lawrence et al. ${ }^{[6]}$ has noted that such effects might be important in residential treatment settings in which participants live in close proximity for extended periods. Benefits associated with anger management training might also have influenced BART participants. Skills in conflict management, responding productively to peer pressure and giving and receiving effective verbal feedback were components of the AM intervention which can be utilized in managing behavioral transactions involving drug use and HIV risk.

It is also possible that neither treatment condition contributed meaningfully to reductions in risk behavior. Substance abuse treatment alone has been linked with meaningful reductions in HIV risk behaviors ${ }^{[32]}$. However, the meaningful reductions seen in both groups were not attributable to pretreatment levels of substance use or to treatment-linked changes in such use. Both intake and follow-up levels of marijuana, alcohol and cocaine use were controlled in all analyses involving changes in sex risk behaviors.

Our study targeted youth between 13-19 years of age. While some might consider this young, research has shown that 14 years is the crucial age at which engagement in sexual behavior and substance use increase ${ }^{[12]}$. Research has also shown that targeted, evidence-based interventions have the greatest chance of reducing risky behaviors, in this case, substance abuse among court-involved adolescents ${ }^{[33]}$. It is important that interventions be sensitive to the needs of these youth as they may have negative perceptions of health care professionals. Furthermore, we cannot forget the wider context in which these youth live and survive. Future programs should include HIV education as well as interventions to address often overwhelming social and economic pressures ${ }^{[9]}$.

\section{CONCLUSION}

The following limitations to the study should be noted. The interventions were conducted while participants were in court-mandated residential treatment. While participation in the research project was voluntary, involvement in residential drug treatment was not. The legally mandated nature of drug treatment may have had a substantial effect on both drug use and HIV-risk reductions in both groups. Further, intervention effects may have "spilled-over" from M-BART to AM participants and vice-versa to 
some degree, thus affecting the distinctiveness of the treatment conditions. These factors might have contributed to lack of hypothesized treatment condition differences in outcome. Finally, we relied upon selfreports of sexual risk and drug use behaviors. Although we took steps to encourage honest responding (i.e., assurance of confidentiality), some degree of misrepresentation seems likely. Despite these limitations, results from this study support previous demonstrations of the feasibility of conducting small group-HIV risk reduction interventions for at-risk ethnic-minority youth ${ }^{[17]}$. This study also suggests the usefulness of translational research: tailoring an evidence-based intervention (BART) to the requirements of an understudied and underserved group of drug abusing minority adolescents.

\section{ACKNOWLEDGEMENT}

This research was funded in part by RO1 DA11875 from NIDA and RO1 AA11752 from NIAAA to Dr. Malow.

\section{REFERENCES}

1. Centers for Disease Control and Prevention, 2005. HIV/AIDS surveillance report. Volume 16. http://www.cdc.gov/hiv/topics/surveillance/resourc es/reports/2004report/table1.htm

2. Henry J. 2002. The tip of the iceberg: The global impact of HIV/AIDS on youth. http://www.kff.org/hivaids/6043-index.cfm

3. Centers for Disease Control and Prevention, 2003. Youth risk behavior surveillance-United States. MMWR., 53: 1-29.

http://new.vawnet.org/category/documents.php?do cid $=643$

4. Centers for Disease Control and Prevention, 2006. Fact sheets: HIV/AIDS among youth. http://www.cdc.gov/hiv/resources/factsheets/youth. htm

5. Helms, J.L. and C.A. Hirbour, 2004. HIV and juvenile delinquency. Am. J. Forensic Psychol., 22: 57-71.

http://direct.bl.uk/bld/PlaceOrder.do?UIN=150870

093\&ETOC $=$ RN\& from $=$ searchengine

6. St. Lawrence, J.S., R.A. Crosby and R.III. O'Bannon, 1999. Adolescent risk for HIV infection: Comparison of four high risk samples. J. HIV/AIDS Prevent. Educ. Adolescents Children, 3: 63-86.

http://cat.inist.fr/?aModele=afficheN\&cpsidt=1521830
7. Kelly, P.J., J. Morgan-Kidd, J.D. Champion and R. Wood, 2003. Sexuality knowledge, attitudes and practices of young women in the juvenile justice system. Pediat. Nurs., 29: 271-275. http://cat.inist.fr/?aModele=afficheN\&cpsidt=15081155

8. Weist, M.D., D.A. Paskewitz, C.Y. Jackson and D. Jones, 1998. Self-reported delinquent behavior and psychosocial functioning in inner-city teenagers: A brief report. Child Psychiatr. Hum. Develop., 28 : 241-248. http://www.ncbi.nlm.nih.gov/pubmed/9628056

9. Lichtenstein, B., 1999. Sex, drugs and HIV risk among detained adolescents in West Alabama. Proceeding of the American Sociological Association National Meeting, Aug. 9-13, Chicago, IL.

10. Vermeiren, R., I. Jespers and T. Moffit, 2006. Mental health problems in juvenile justice populations. Child Adolescent Psychiatr. Clin, North Am., 15: 333-351. http://linkinghub.elsevier.com/retrieve/pii/S105649 9305001240

11. Teplin, L.A., K.S. Elkington, G.M. McClelland, K.M. Abram, A.A. Mericle and J.J. Washburn, 2005. Major mental disorders, substance use disorders, comorbidity and HIV-AIDS risk behaviors in juvenile detainees. Psychiatr. Servic., 56: 823-828.

http://psychservices.psychiatryonline.org/cgi/conte nt/abstract/56/7/823

12. Mellins, C.A., E. Brackis-Cott, C. Dolezal and H.F.L. Meyer-Bahlburg, 2005. Behavioral risk in early adolescents with HIV+mothers. J. Adolesc. Health, 36: 342-351. http://www.ncbi.nlm.nih.gov/pubmed/15780790

13. St. Lawrence, J.S., T.L. Brasfield, K.W. Jefferson, B.R.E. Alleyne and A. Shirley, 1995. Cognitivebehavioral intervention to reduce AfricanAmerican adolescents' risk for HIV infection. J. Consult. Clin. Psychol., 63: 221-237. http://www.ncbi.nlm.nih.gov/pubmed/7751483

14. Solomon, J., J.J. Card and R.M. Malow, 2006. Adapting efficacious interventions: Advancing translational research in HIV prevention. Eval. Health Prof., 29: 162-194. http://www.ncbi.nlm.nih.gov/pubmed/16645183

15. Rosenberg, R. and R.M. Malow, 2006. The hardness of risk: Poverty, women and new targets for HIV/AIDS prevention. Psychology and AIDS, (special issue on poverty). Am. Psychol. Assoc., 34: 3-12. 
16. Rosenberg, R. and R.M. Malow, 2008. The Hard Science of Hard Risks in Women's HIV Prevention: Making Biology Part of the Context. In: HIV/AIDS: Global Frontiers in Prevention/Intervention, C. Pope, R. White and R. Malow (Eds.). Routledge, New York.

17. St. Lawrence, J.S., R.A. Crosby, T.L. Brasfield, R.E. III O'Bannon, 2002. Reducing STD and HIV risk behavior of substance-dependent adolescents: A randomized controlled trial. J. Consult. Clin. Psychol., 70: 1010-1021. http://www.ncbi.nlm.nih.gov/pubmed/12182264

18. Otto-Salaj, L.L., T.G. Heckman, L.Y. Stevenson, J.A. Kelly, 1998. Patterns, predictors and gender differences in HIV risk among severely mentally ill men and women. Commun. Ment Health J., 34: 175-90.

http://www.ncbi.nlm.nih.gov/pubmed/9620162

19. Malow, R.M. and S.J. Ireland, 1996. HIV risks correlates among non-injection cocaine dependent men in treatment. AIDS Educ. Prevent., 8: 226-235. http://www.ncbi.nlm.nih.gov/pubmed/8806951

20. Malow, R.M., J.G. Dévieux, T.E. Jennings, B. Lucenko and S. Kalichman, 2001. Substance abusing adolescents at varying levels of HIV risk: Psychosocial characteristics, drug use and sexual behavior. J. Subst. Abuse, 13: 103-117. http://www.ncbi.nlm.nih.gov/pubmed/11547612

21. Sobell, L.C. and M. B. Sobell, 1980. Convergent Validity: An Approach to Increasing Confidence in Treatment Outcome Conclusions with Alcohol and Drug Abusers. In: Evaluating Alcohol and Drug Abuse Treatment Effectiveness: Recent Advances, Sobell, L.C., M.B. Sobell and E. Ward (Eds.). Pergamon Press, New York, pp: 177-183.

22. Rockville, M.D., 1991. National institute on drug abuse.

23. Kauth, M.R., J.S. St. Lawrence, J.A. Kelly, 1991. Reliability of retrospective assessments of sexual HIV risk behavior: A comparison of biweekly, three-month and twelve-month self-reports. AIDS. Educ. $\quad$ Prevent., 3: 207-214. http://www.ncbi.nlm.nih.gov/pubmed/1834142

24. Jemmott, L.S., J.B. Jemmott, and K.A. McCaffree, 1994. Be proud! be responsible! strategies to empower youth to reduce their risk for HIV infection. Columbia University School of Nursing, New York. http://www.neahin.org/programs/reproductive/wor ks/proud.htm
25. Rotheram-Borus, M.J., S. Miller, C. Koopman, C. Haignere, and C. Selfridge, 1993. Adolescents Living Safely: AIDS Awareness, Attitudes and Actions. (Manual). HIV Center for Clinical and STDs and HIV: A Guide for Today's Young Adults. New York.

26. Yarber, W.L., 1992. STDs and HIV: A Guide for Today's Young Adults. (Manual). American Alliance for Health, Physical Education, Recreation and Dance, Reston, VA., ISBN: 10: 0883145332, pp: 100.

27. St. Lawrence, J.S., 1994a. Becoming a responsible teen: An HIV risk reduction intervention for African-American adolescents. (Manual). Jackson, MS: Jackson State University.

28. Hammond, W.R., B.R. Yung and P. Kadis, Positive Adolescent Choices Training. ERIC Document. http://www.state.sc.us/dmh/schoolbased/pact.htm

29. SPSS., 2003. SPSS 12.0 Brief Guide. SPSS Publisher, Prentice Hall.

30. Dévieux, J., R. Malow, J.A. Stein, T.A. Jennings, B.A. Lucenko, C. Averhart and S. Kalichman, 2002. Impulsivity and HIV risk among adjudicated alcohol-and other drug-abusing adolescent offenders. AIDS. Educ. Prevent., 14: 24-35. http://cat.inist.fr/?aModele $=$ afficheN\&cpsidt $=1401$ 0667

31. Thompson, L.L., E.A. Whitmore, K.M. Raymond and T.J. Crowley, 2006. Measuring impulsivity in adolescents with serious substance and conduct problems. Assessment, 13: 3-15. http://www.ncbi.nlm.nih.gov/pubmed/16443715

32. Metzger, D.S., H. Nevaline and G.E. Woody, 1998. Drug treatment as AIDS prevention. Public Health Rep., $\quad$ 113: 97-106. http://www.pubmedcentral.nih.gov/articlerender.fc gi? artid $=1307732$

33. Henggeler, S.W., C.A. Halliday-Boykins, P.B. Cunningham, J. Randall, S. B. Shapiro and J.E. Chapman, 2006. Juvenile drug court: Enhancing outcomes by integrating evidence-based treatments. J. Consult. Clin. Psychol., 74: 42-54. http://www.ncbi.nlm.nih.gov/pubmed/16551142 